\title{
Interpersonal Communication of School Students in Physical Experimental Activity: The Aspect of Real and Digital Labs
}

\author{
Palmira Peciuliauskiene \\ Lithuanian University of Educational Sciences; palmira.peciuliauskiene@leu.lt
}

Doi:10.5901/ajis.2015.v4n3s1p679

\section{Abstract}

\begin{abstract}
The article deals with Lithuanian secondary school students' attitudes towards interpersonal communication in real (with traditional laboratory instruments) and digital physics laboratory work (labs). Performing laboratory work in physics, students work in groups where they can communicate, exchange technical information, and provide assistance to each other. Interpersonal communication between students depends of the forms of laboratory work: real or digital. In comparison to digital laboratory work, students can communicate with each other more doing real laboratory work. This has led to a scientific problem, which is formulated as a question: What is the attitude of school students to the real and digital physics labs and their role in interpersonal communication? The aim of the research is to disclose the role of real and digital physics labs in the secondary school students' interpersonal communication. Real and digital laboratory work in physics was carried out in accordance with the second stage of inquiry based learning, namely structured inquiry. This method encouraged students to communicate and collaboratively search for an unknown result of a lab. The study was based on interpersonal communication model on the three levels of communication: I-It; I-You; I-Thou. The interpersonal communication of students was assessed in the following aspects: interpersonal distance, interpersonal trust, and interpersonal communication in terms of expectations and friendship. The study based on ANOVA data block revealed the attitude of the school students towards the real and digital physics labs, their role in the nature of interpersonal communication (interpersonal distance, interpersonal trust, interpersonal expectations).
\end{abstract}

Keywords: interpersonal communication, real physical labs, digital physical labs.

\section{Introduction}

Educational practice is based on subject-specific communication, yet it is impossible without interpersonal communication. J. Wood (2013) provides a definition of interpersonal communication, which reveals the significance of interpersonal communication in the process of learning. The meaning of the word interpersonal is derived from the prefix inter (or between) and the word person. The best way to define interpersonal communication is by focusing on what happens between people, not where they are or how many are present. Interpersonal communication is a selective, systemic, individual, processual transaction that allows people to reflect and build personal knowledge of one another and create shared meanings (Wood, 2013). Such an approach to interpersonal communication is related to constructivist theory of learning, which maintains that personal knowledge is not complete and invariable or transferrable. Knowledge is partly personalized (subjective), as the meaning is constructed by a person referring to own experience. Hence, it is evident that interpersonal communication in a comprehensive school is determined by the learning environment and the content of school subjects. The laboratory is a key site for science education. It is here that discipline knowledge and generic competences are fused and honed, in the very act of 'doing science' (Hintona, Yeomanc, Carvalhob et al., 2014). The classroom laboratory is the area were school students learn science by 'doing science'. The laboratory facilitates the application of theoretical concepts and key principles in a discipline. Laboratories create opportunities for school students to apply knowledge in 'real world' and experimental contexts and to engage in practices similar to those of experts (deHaan, 2005). The classroom laboratory provides collaboration and encourages the students to work in teams on common outcomes. "Activity - what students actually do - is shaped by (1) the tasks they are asked to tackle, (2) the physical setting, and (3) the social organization of their work (e.g. how tasks are distributed across members of a team). While tasks, setting and social arrangements can be designed in advance, learner activity cannot" (Hintona, Yeomanc, Carvalhob et al., 2014).

Interpersonal communication in the classroom laboratory can be supported by different levels of inquiry-based learning. H. Banchi \& R. Bell (2008) identify four levels of inquiry-based learning: confirmation inquiry, structured inquiry, guided inquiry and open enquiry. The lowest level of inquiry (confirmative inquiry) corresponds to activities where learners 
know the possible outcomes of a project, and where a detailed description of activities and problems is provided. The second level of inquiry (structured inquiry) is reached in projects when learners are provided with a problem and the method for its solution. The third level (coordinated inquiry) is characterized by the fact that learners know the problem but have to find out how to solve it by themselves. The highest level (open inquiry) is reached when learners identify a problem, methods for its solution, and explanations for the curricular phenomena themselves. In these labs, students generate scientific evidence and explanations while designing and conducting their own experimental investigations (Etkina, Karelina, Ruibal-Villasenor et al., 2010). Low interpersonal communication is acquired by confirmation inquiry, a higher interpersonal communication is gained by structured inquiry and guided inquiry, whereas the highest interpersonal communication is obtained by open enquiry. The article deals with the application of the structured inquiry in Physics labs for the interpersonal communication.

The physics labs can be real or digital. There are various ways of defining digital labs. They can be defined as a computer program that allows a student to run simulated experiments via the web or as a stand-alone application. A digital lab could be a set of simulations put together (Examples are applets, flash base demos, animations) (Bajpai, 2013). Scientific literature reveals many features of digital labs: the tools are less time-consuming, more flexible, clean, rapid and safe; moreover, they open up for types of experimentation that otherwise might not be possible for students to engage in (Dalgarno \& Lee, 2010; Petersson, Andersson \& Säljö, 2013).

There is a discussion about the role of real and digital labs in education. It is argued that there is no simple answer to the dilemma which laboratory is best for students. All types of laboratories offer certain advantages. The balanced mixture of real, virtual and remote labs should be offered for students (Nedic, Machotka \& Nafalski, 2003), both forms of activity have unique properties that are needed to promote deeper conceptual understanding (Jaakkola \& Nurmi, 2008; Winn et al., 2006). However, there is a lack of discussion how real and digital labs determine interpersonal communication of school students.

The scientific problem is formulated as a question: what experimental activity promotes interpersonal communication among the learners of the new generation in a lesson of physics? The research problem highlights the object of the research: interpersonal communication of basic school students. It also determines the aim of the research: to explore how physical experimental activity based on structured investigation determines learners' interpersonal communication.

\section{Objectives of the Research}

1. To explore the effect of real and digital physics labs on learners' interpersonal communication.

2. To reveal the role of real and digital labs in the interpersonal interaction of learners according to the levels of communication (I-It, I-You; I-Thou).

\section{Theoretical Background}

The phenomenon of inquiry-based learning is impacted by technologies. Learning environment can facilitate students' involvement in experimental design, data collection, data analysis and discussion inside and outside classroom. The physics experimental activity is a constructive and cooperative learning process. At this activity school students discuss, search for, integrate auxiliary information, reflect experiments, and share the meaning either in writing or in speaking. The positive interdependence, promotive interaction, individual accountability, social skills, group processing prove that learners work cooperatively (Lo, 2013). All these activities are related to communication. Interpersonal communication among school students depends on the forms of laboratory work: real or digital. Contrary to digital laboratory work, students can communicate with each other more by doing real laboratory work.

On the other hand, the phenomenon of inquiry-based learning is impacted not only by technologies but also by changing generations. According to the sociological classification, persons born in 1977-1994 belong to Generation Y, whereas the ones born in 1995-2012 belong to Generation Z (McCrindle \& Wolfinger, 2010). Currently, learners of Generation Z attend comprehensive school. The relationship of Generation Z with technologies has been precisely defined by A. Cross-Bystrom (2010): 'Generation Z is technology'. The statement presupposes a very close relationship with technologies since the generation itself is equalled to technologies. Learners of this generation have lived in the world closely intertwined with technologies since early childhood (Cross-Bystrom, 2010). Californian psychologist L. D. Rosen (2012) raises a question about what teachers know about young people who spend entire hours by the computer in different social networks. L. D. Rosen's question can be restated as follows: what do teachers know about the 
interpersonal communication of learners of Generation Z studying natural sciences and how is it affected by real and digital labs? Is the communication between school students at physics labs interpersonal? "Much of our communication is not really personal. Sometimes we don't acknowledge others as people at all and treat them as objects $<\ldots>$ In other instances, we do acknowledge people, yet we interact with them in terms of their social roles rather than personally". (Wood, 2013; p.18).

Communication exists like a continuum from impersonal to interpersonal communication (Wood, 2013). Philosopher Marin Buber (1970) distinguishes three levels of communication in this continuum: I-It, I-You; I-Thou. In the I-It level we treat others very impersonally, we do not acknowledge the humanity of other people and treat them as objects. At the second communication level (I-You) people acknowledge one another as more than objects, they recognize others as individuals within those roles, but they do not fully engage each other. At the level I-You the interaction is guided by the social roles of people (classmates, members of a team). "In the workplace, most of us have many I-You relationships" (Wood, 2013, p.19). The highest form of human dialogue is I-Thou communication. We open ourselves fully and accept others totally at the third level. According to M. Buber (1970), people became fully human in IThou relationship. Hence, it is topical to investigate what level of communication school students of Generation Z reach while performing physics laboratory work; and how interpersonal communication (according communication levels) influences real and digital labs by the following aspects: interpersonal distance, interpersonal trust, and interpersonal communication in terms of expectations and friendship.

\section{Methodology}

The research methodology is based on constructivist theory of education, which acknowledges structured inquiry as an efficient educational technology promoting interpersonal communication, a positive attitude towards the subjects of natural sciences and helping to apply the acquired knowledge in different situations, developing higher-level thinking abilities as well as promoting active learning processes that are based on knowledge and experience. Moreover, realist education philosophy stating that the reality of natural sciences is objective and cognisable is considered. The constructivist theory of learning tells that learning is an active process based on individual personal experiences and the knowledge is the personal understanding of the reality through personal experience (Igwebuike \& Oriaifo, 2012; Ongowo, Indoshi \& Ayere, 2014).

\section{The Instrument of Quantitative Research}

Intrinsic Motivation Inventory (IMI) was used intended to assess participants' subjective experience related to target activity in laboratory experiments (Ryan, 1982). There are seven subscales in this instrument: the subscale of participants' interest/enjoyment, perceived competency, effort, value/usefulness, felt pressure and tension, perceived choice (or autonomy of activity) and relatedness. The seventh subscale (interpersonal interactions) of IMI assesses the interpersonal communication of learners in experimental activity. This subscale describes thoughts and feelings of learners which they may have had regarding another person who participated in the experiment (1. I felt really distant to this person; 2. I really doubt that this person and I would ever be friends; 3. I felt like I could really trust this person; 4. I'd like a chance to interact with this person more often; 5 . I'd really prefer not to interact with this person in the future; 6.1 don't feel like I could really trust this person; 7. It is likely that this person and I could become friends if we interacted a lot; 8. I feel close to this person). The results of seventh subscale in our research are represented by the interval scale, which ranges from 1 to 100 points.

Our study is based on interpersonal communication model in terms of the three levels of communication: I-It; I-You; I-Thou. The different levels of interpersonal communication of school students are assessed in the following aspects: interpersonal distance (level I-It), interpersonal communication in terms of expectations and friendship (level I-You) and interpersonal trust (level I-Thou) (Table 1). The statements about interpersonal communication from IMI subscale are related with the levels of communication (Buber, 1970) (Table 1).

Table 1. The levels of communication (by Buber) and the statements about interpersonal communication (by IMI)

\begin{tabular}{|c|l|c|l|}
\hline \multicolumn{2}{|l|}{ Level of communication } & $\begin{array}{l}\text { The number of } \\
\text { Statement in IMI }\end{array}$ & $\begin{array}{l}\text { The statement about interpersonal communication of } \\
\text { seventh subscale by IMI }\end{array}$ \\
\cline { 2 - 4 } I-It & Interpersonal distance & 1 & I felt really distant to this person \\
\cline { 2 - 3 } & 6 & I don't feel like I could really trust this person \\
\hline
\end{tabular}




\begin{tabular}{|c|l|c|l|}
\hline \multirow{2}{*}{ I-You } & \multirow{2}{*}{$\begin{array}{l}\text { Interpersonal communication in terms } \\
\text { of expectations and friendship }\end{array}$} & 7 & $\begin{array}{l}\text { It is likely that this person and I could become friends if } \\
\text { we interacted a lot }\end{array}$ \\
\cline { 3 - 4 } & & 4 & l'd like a chance to interact with this person more often \\
\hline \multirow{2}{*}{ I-Thou } & Interpersonal trust & 8 & I feel close to this person \\
\cline { 3 - 4 } & & 3 & I felt like I could really trust this person \\
\hline
\end{tabular}

\subsection{The sample and sampling of quantitative research}

The research sample is reliable and representative (probability cluster sample). The sample includes eighth-form learners of Lithuania. The research clusters are the largest cities of Lithuania. Classes have been selected on the basis of probability cluster sample and all learners of a selected class have been tested.

The research sample is reliable as it involves 385 school students. The total population was 25000 eighth-form school students (EMIS - Education Management Information System). The confidence interval being 5\%, confidence level is $95 \%$. Hence, the research sample should have included 379 respondents. Therefore, the probability (confidence level) is $95 \%$, so the obtained data can shift only by $5 \%$ from the population parameters (confidence interval).

\section{Method of Research}

The school students accomplished a Physics lab using real laboratory and digital laboratory software Xplorer GLX. It is a tool of storage, presentation and analysis of the data of experimental measurements that operates with PASPORT sensors.

The school students were working in groups: on average three persons per group. In terms of inquiry-based levels, the lab conformed to the second level (structured inquiry). Before the accomplishment of the lab, the school students were introduced to the aim and procedure of the work, but they were not familiar with the result. After the accomplishment of three real labs and after the accomplishment three digital labs, the learners filled in the IMI questionnaire that was meant for interpersonal communication. Each statement in IMI questionnaire about interpersonal communication was assessed by each student. We have done the analysis only of seventh subscale of IMI in this article.

\section{Results}

\subsection{Assessment of interpersonal communication following the IMI subscale of interpersonal communication: real and digital labs}

The school students assessed interpersonal communication in terms of the IMI subscale interpersonal interactions after the accomplishment of two cycles of laboratory work in physics. The first cycle of physics labs consisted of three labs that were accomplished by common laboratory devices (Real labs). The second cycle of laboratory work comprised three labs conducted using digital laboratory devices (Digitals labs). Students' attitude towards interpersonal communication while conducting real and digital labs is presented in square diagrammes box plot (Pict. 1).

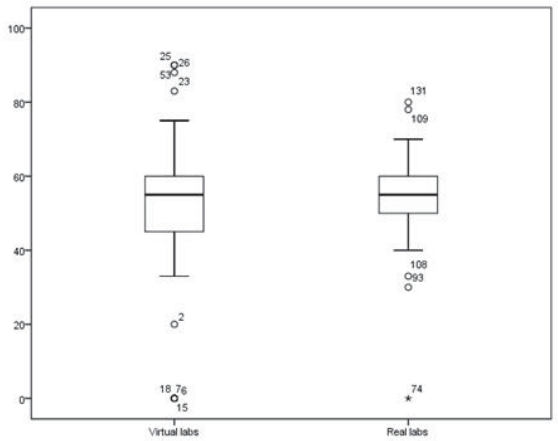

Picture 1. Assessment of learners' interpersonal communication in cases of real and virtual labs 
The box plot (Pict. 1) reveals common tendencies of the distribution of the meanings of the quantitative variable: spread, and maximal and minimal meanings. The upper bound of the square diagramme conforms to the third quartile $\left(\mathrm{Q}_{3}\right)$, whereas the lower bound conforms to the first quartile $\left(\mathrm{Q}_{1}\right)$. The difference between the upper $\left(\mathrm{Q}_{3}\right)$ and lower $\left(\mathrm{Q}_{1}\right)$ quartile defines the spread of the data and is referred to as Interquartile Range (IQR), which covers $50 \%$ of the total data. The research data showed that IQR of interpersonal interaction differed in virtual and real laboratory work. In the case of real laboratory work, IQR $=10,50$, as $\mathrm{Q}_{3}=60,00, \mathrm{Q}_{1}=49,50$. Hence, $50 \%$ of research participants assessed interpersonal communication while accomplishing real labs from 49,50 to 60,00 points. In the case of virtual labs, IQR $=15,00$, as $Q_{3}=$ $60,00, Q_{1}=45,00$ (Pict. 1). The bigger IQR of virtual labs means that the spread of the data on interpersonal communication assessment was bigger (Pict. 1).

The research data demonstrate (Pict. 1) that the median (quartile $\mathrm{Q}_{2}$ ) of interpersonal communication coincides in the cases of real and virtual labs $\left(\mathrm{Mdr}^{1}=\mathrm{Mdd}^{2}=55,00\right)$. The median divides the rank order by half (all the meanings are arranged in the increasing order). Hence, the median presupposes the variable meaning, below which appear half of all the meanings, and another half appear above it. Despite the fact that the medians of the students' assessment of interpersonal communication in the cases of real and virtual labs coincided, their means were different (Table 2). $t$ test for dependent samples was applied to assess the difference. It showed that the different in students' assessment of interpersonal communication in the cases of real and virtual labs was not statistically significant $(t=0,723 ; d f=65 ; p=$ $0,472)$.

Table 2. Assessment of learners' interpersonal communication in cases of real and digital labs

\begin{tabular}{|l|c|c|}
\hline & Digital labs & Real labs \\
\hline Mean & 52,00 & 54,74 \\
\hline Median & 55,00 & 55,00 \\
\hline Std. Deviation & 19,632 & 11,283 \\
\hline Skewness & $-1,064$ & $-1,715$ \\
\hline
\end{tabular}

The assessment of students' interpersonal communication in the cases of real and virtual labs has deviances that are set further from the median of the distribution in one or another direction (Pict. 1). They are called abnormal or atypical meanings. Four abnormal meanings were found $\left(\right.$ marked $^{\circ}$ ), that fell into the yellow card zone (outlier) in the cases of real labs. In the case of real labs, one atypical meaning was found that fell into the red card zone (extreme) (Pict. 1). Five abnormal meanings (the yellow card zone) were found in the cases of digital labs. These deviances had effect on the skewness of the distribution. The research data show that the distributions of the assessment of school students' interpersonal communication was marked by left skewness $A_{s}<0$. In the case of digital labs, the left negative skewness $\left(A_{s}=-1.064\right)$ was weaker than the negative skewness of the real labs $\left(A_{s}=-1.715\right)$. Consequently, the statements defining the students' assessment of interpersonal communication received higher evaluation in the case of real labs. As it was states before, the differences in the assessment of students' interpersonal communication was not confirmed by $t$ test results $(t=0,723 ; d f=65 ; p=0,472)$.

\subsection{Assessment of interpersonal communication in terms of communication levels: real labs}

The research involved the study of the role of real labs in students' interpersonal communication in terms of the levels of communication: level I-It (interpersonal distance), level I-You (interpersonal communication in terms of expectations and friendship) and level I-Thou (interpersonal trust) (Table 1). Pursuing to compare the statements defining interpersonal communication in terms of different levels, variance analysis of blocked data (Repeated Measures) ANOVA was used. The results of the four criteria of ANOVA blocked data coincided. Hence, assumed sphericity was attained; therefore the assessment of interpersonal communication was analysed according to the criterion of sphericity. It confirmed the statistical significance $(p=0,000)$ of the differences in the assessment of interpersonal communication, when the level of significance is $a=0,05$.

Applying ANOVA blocked data, the means of the assessment points for interpersonal communication were

\footnotetext{
1 The median of real lab (r).

${ }^{2}$ The median of digital lab (d).
} 
calculated in terms of different communication levels (Table 3). The mean points of the statements compliant to the I-It level of communication were the lowest: I felt really distant to this person ( $\left.\bar{x}_{r 1}=40,30 \pm 3,46\right)$; I don't feel like I could really trust this person $\left(\bar{x}_{r 4}=43,33 \pm 3,41\right)$; whereas the mean points of statements compliant with the I-You and I-Thou level were the highest: It is likely that this person and I could become friends if we interacted a lot ( $\left.\bar{x}_{r 5}=69,39 \pm 3,67\right)$; I felt like I could really trust this person $\left(\bar{x}_{r 2}=72,42 \pm 3,63\right)$.

Table 3. Levels of interpersonal communication and the compliant mean points of the assessment statements: real labs

\begin{tabular}{|c|c|c|c|c|c|}
\hline \multirow[b]{2}{*}{ Level, factor ${ }^{3}$} & \multirow[b]{2}{*}{ Statement about interpersonal communication } & \multirow[b]{2}{*}{ Mean } & \multirow[b]{2}{*}{ Std. Error } & \multicolumn{2}{|c|}{ 95\% Confidence Interval } \\
\hline & & & & $\begin{array}{l}\text { Lower } \\
\text { Bound }\end{array}$ & $\begin{array}{l}\text { Upper } \\
\text { Bound }\end{array}$ \\
\hline \multirow{2}{*}{$\begin{array}{l}\text { I-It (1) } \\
\text { I-It (4) }\end{array}$} & I felt really distant to this person & 40,303 & 3,468 & 33,377 & 47,229 \\
\hline & I don't feel like I could really trust this person & 43,333 & 3,416 & 36,511 & 50,156 \\
\hline \multirow{2}{*}{$\begin{array}{l}\text { I-You (3) } \\
\text { I-You (5) }\end{array}$} & I'd like a chance to interact with this person more often & 67,273 & 3,472 & 60,339 & 74,206 \\
\hline & $\begin{array}{l}\text { It is likely that this person and I could become friends if we } \\
\text { interacted a lot }\end{array}$ & 69,394 & 3,670 & 62,065 & 76,723 \\
\hline \multirow{2}{*}{$\begin{array}{l}\text { I-Thou (2) } \\
\text { I-Thou (6) }\end{array}$} & I felt like I could really trust this person & 72,424 & 3,633 & 65,169 & 79,679 \\
\hline & I feel close to this person & 65,758 & 3,784 & 58,201 & 73,314 \\
\hline
\end{tabular}

The difference in the mean points of the statements evaluating interpersonal communication can be explained by the different character of the content of statements. The statement about interpersonal communication at first level I-It have a negative character: I felt really distant to this person, I don't feel like I could really trust this person. The statements about interpersonal communication at second and third level have a positive character: l'd like a chance to interact with this person more often; It is likely that this person and I could become friends if we interacted a lot, I felt like I could really trust this person, I feel close to this person. The mean of statements having negative character was about $20 \%$ lower than the positive ones. Consequently, it is assumed that interpersonal communication that occurs in the case of real labs has positive character.

ANOVA blocked data allows to compare the assessment of different statements about interpersonal communication among themselves; Bonferoni criterion was used to define the statistical significance of the differences of assessment (Table 4). Bonferoni criterion showed that the assessment of the statements about interpersonal communication that complied to the I-It level (I felt really distant to this person, I don't feel like I could really trust this person) statistically significantly differed from the other levels of the assessment of the statements about interpersonal communication. The difference between the first (I felt really distant to this person) and the fourth (I don't feel like I could really trust this person) factors of I-It level was statistically insignificant.

Table 4. Results of ANOVA Bonferoni data block test. Pairwise Comparisons of interpersonal communication factors in real labs

\begin{tabular}{|c|c|c|c|c|c|c|}
\hline \multirow{2}{*}{ (I) factor1 } & \multirow{2}{*}{ (J) factor1 } & \multirow{2}{*}{ Mean Difference (I-J) } & \multirow{2}{*}{ Std. Error } & \multirow{2}{*}{ Sig. ${ }^{a}$} & \multicolumn{2}{|c|}{ 95\% Confidence Interval for Differencea } \\
\hline & & & & & Lower Bound & Upper Bound \\
\hline \multirow{5}{*}{1 (I-It, distance) } & 2 (I-Thou, trust) & $-32,121^{*}$ & 5,919 & 000 & $-43,942$ & $-20,300$ \\
\hline & 3 (I-You, intent interact) & $-26,970^{*}$ & 5,505 & 000 & $-37,963$ & $-15,976$ \\
\hline & 4 (I-It, distrust) & $-3,030$ & 3,987 & 450 & $-10,993$ & 4,932 \\
\hline & 5 (I-You, intent be friends) & $-29,091^{*}$ & 5,327 &, 000 & $-39,730$ & $-18,452$ \\
\hline & 6 (I-Thou, closeness) & $-25,455^{\star}$ & 5,992 &, 000 & $-37,422$ & $-13,487$ \\
\hline
\end{tabular}

Based on estimated marginal means.

*.The mean difference is significant at the, 05 level.

a. Adjustment for multiple comparisons: Least Significant Difference (equivalent to no adjustments).

The results of ANOVA blocked data (Table 4) demonstrated that statistically significant differences were found between

${ }^{3}$ The same numbering of factors was applied as in the case of ANOVA blocked data (Table 4). 
the statements of negative character (factor 1 and factor 4 ) and among all the statements of positive character (factor 2 , factor 3 , factor 5 , factor 6 ) about interpersonal communication $(p=0,000)$. Statistically significant differences between negative statements about interpersonal communication were not defined $(p=0,450)$.

\subsection{Assessment of interpersonal communication in terms of communication levels: digital labs}

The digital and real labs were conducted following the structure inquiry methodology. In case of structured inquiry, students do not know the answer in advance, but are rather encouraged to search for it, which stimulates their interpersonal communication. Digital labs were conducted using digital laboratory software Xplorer GLX that generates final results of the work, draws data tables and drawings. In other words, the search for results is accomplished by computer software. Consequently, the duration of a lab is shortened as well as the time of interpersonal communication in the real setting. The role of digital labs in students' interpersonal communication was explored using structured inquiry according to communication levels: level I-It (interpersonal distance), level I-You (interpersonal communication in terms of expectations and friendship) and level I-Thou (interpersonal trust) (Table 5).

Table 5. Levels of interpersonal communication and the compliant mean points of the assessment statements: digital labs

\begin{tabular}{|c|l|c|c|c|c|}
\hline \multirow{2}{*}{ Level, factor } & Statement about interpersonal communication & \multirow{2}{*}{ Mean } & Std. Error & \multicolumn{2}{c|}{ 95\% Confidence Interval } \\
\cline { 3 - 6 } & & & Lower Bound & Upper Bound \\
\hline I-It (1) & I felt really distant to this person & 36,364 & 3,051 & 30,271 & 42,456 \\
\cline { 2 - 6 } I-It (4) & I don't feel like I could really trust this person & 42,424 & 3,728 & 34,980 & 49,869 \\
\hline I-You (3) & I'd like a chance to interact with this person more often & 64,545 & 3,977 & 56,604 & 72,487 \\
\cline { 2 - 5 } I-You (5) & It is likely that this person and I could become friends if we interacted a lot & 63,939 & 4,056 & 55,839 & 72,040 \\
\hline I-Thou (2) & I felt like I could really trust this person & 68,485 & 4,029 & 60,438 & 76,532 \\
\cline { 2 - 6 } I-Thou (6) & I feel close to this person & 62,727 & 4,048 & 54,642 & 70,812 \\
\hline
\end{tabular}

The research data showed that the lowest mean of points was among the statements compliant to the I-It level of communication: I felt really distant to this person $\left(\bar{x}_{d 1}=36,36 \pm 3,05\right)$, I don't feel like I could really trust this person ( $\bar{x}_{d 4}$ $=42,42 \pm 3,72$ ). The highest mean of points was attributed to the statements compliant with the I-You and I-Thou level of communication l'd like a chance to interact with this person more often $\left(\bar{x}_{d 3}=64,54 \pm 3,97\right)$, I felt like I could really trust this person $\left(\bar{x}_{d 2}=68,48 \pm 4,02\right)$. Comparing the assessment of the statements defining interpersonal communication according to the levels of communication in the cases of real (Table 3) and digital labs (Table 5), the same tendencies were observed. The lowest mean points are noted for the statements compliant with the I-It level of communication, and the highest mean points are observed for the statements compliant with the I-You and I-Thou levels of communication.

The results of ANOVA blocked data of digital labs (Table 6) showed that statistically significant differences were found between the statements compliant to the I-It communication level (factor 1 and factor 4) and among all the statements of I-You and I-Thou levels of communication (factor 2 , factor 3 , factor 5 , factor 6$)(p=0,000)$. Statistically significant differences between the statements compliant to the I-It level were not defined $(p=0,450)$. The same regularities were observed in the case of real labs (Table 4).

Table 6. Results of ANOVA Bonferoni data block test. Pairwise Comparisons of interpersonal communication factors in digital labs

\begin{tabular}{|c|c|c|c|c|c|c|}
\hline \multirow{2}{*}{ (I) factor1 } & \multirow{2}{*}{ (J) factor1 } & \multirow{2}{*}{ Mean Difference (I-J) } & \multirow{2}{*}{ Std. Error } & \multirow{2}{*}{ Sig. ${ }^{\mathrm{a}}$} & \multicolumn{2}{|c|}{ 95\% Confidence Interval for Difference } \\
\hline & & & & & Lower Bound & Upper Bound \\
\hline \multirow{5}{*}{1 (I-It, distance) } & 2 (I-Thou, trust) & $-32,121^{*}$ & 4,787 &, 000 & $-41,681$ & $-22,561$ \\
\hline & 3 (I-You, intent interact) & $-28,182^{\star}$ & 4,750 &, 000 & $-37,668$ & $-18,696$ \\
\hline & 4 (I-It, distrust) & $-6,061^{*}$ & 2,960 &, 045 & $-11,971$ &,- 150 \\
\hline & 5 (I-You, intent be friends) & $-27,576^{\star}$ & 4,746 &, 000 & $-37,053$ & $-18,098$ \\
\hline & 6 (I-Thou, closeness) & $-26,364^{*}$ & 5,039 &, 000 & $-36,427$ & $-16,300$ \\
\hline
\end{tabular}

Based on estimated marginal means.

*. The mean difference is significant at the, 05 level.

a. Adjustment for multiple comparisons: Least Significant Difference (equivalent to no adjustments). 
The assessment of statements defining interpersonal communication was compared according to the levels of communication (I-It, I-You, I-Thou) conducting real and virtual labs. The statistical comparison of results was carried out employing $t$ test criterion for two dependent samples (Table 7). The results of t test showed that a statistically significant difference was determined in only one case of comparison evaluating the statement about interpersonal communication It is likely that this person and I could become friends if we interacted a lot $(p=0,030)$. This statistically significant difference occurred due to fact that the statement It is likely that this person and I could become friends if we interacted a lot was assessed with higher points in the case of real labs (Table 3) than of digital labs (Table 5).

Table 7. Comparison of students' statements about interpersonal communication: $t$ test results at real and virtual labs

\begin{tabular}{|c|l|c|c|c|}
\hline Level & Statement about interpersonal communication & $\mathrm{t}$ & $\mathrm{df}$ & Sig. (2-tailed) \\
\hline I-It & I felt really distant to this person &, 822 & 65 &, 414 \\
\cline { 2 - 5 } I-It & I don't feel like I could really trust this person &, 195 & 65 &, 846 \\
\hline I-You & I'd like a chance to interact with this person more often &, 504 & 65 &, 616 \\
\cline { 2 - 5 } I-You & It is likely that this person and I could become friends if we interacted a lot &, 992 & 65 &, 030 \\
\hline I-Thou & I felt like I could really trust this person &, 723 & 65 &, 472 \\
\cline { 2 - 5 } I-Thou & I feel close to this person &, 560 & 65 &, 578 \\
\hline
\end{tabular}

When accomplishing real labs in groups according to the methodology of structures inquiry, assumptions for friendship It is likely that this person and I could become friends if we interacted a lot are formed (Table 7). It is assumed that real labs provide school students with better possibilities to communicate, as well as know people working in the group better. Therefore, their assumptions for friendship in the future are more expressed.

\section{Discussion}

The conducted analysis of the communication of eighth-form school students in terms of the performance of physics labs in the real and digital environment has confirmed the assumption of Z. Nedic, J. Machotka \& A. Nafalski, 2003 that there is no simple answer to the dilemma which laboratory is the best for school students. The results of our research show that assessment of eighth-form school students' interpersonal communication in accordance with IMI social relatedness subscale in real and digital environment is not statistically significant $(t=0,723 ; d f=65 ; p=0,472)$.

The research involved the analysis of the results of Physics labs that are attributed to structured inquiry in terms of the Inquiry Theory (Banchi \& Bell, 2008). A. Loukomies et al. (2013) maintain that, in terms of inquiry strategy, it is important to employ not only learners' prior knowledge but also the basic psychological needs (for autonomy, competency and social relatedness) they want to fulfil. While accomplishing structured inquiry labs, the learners can fulfil a need for social relatedness. They can communicate in groups to search for an unknown outcome of the lab and discuss ideas with peers. The inquiry learners need to design experiments, decide upon appropriate data to collect, as well as to tabulate their findings (Wolf \& Fraser, 2008). Stephen J. Wolf \& Barry J. Fraser (2008) analysed how eighth-form learners explored activity of static electricity and determined that learners in the inquiry classes worked more closely and offered advice and suggestions. According to the sociological characteristics (McCrindle, Wolfinger, 2010) of generations, the research participants in S. J. Wolf \& B. J. Fraser's (2008) study belonged to Generation Y. Hence, social interaction was important for learners of Generation Y while accomplishing real labs in static electricity. The results of our research show that structured inquiry allows social interaction and plays an important role in communication at physics experimental activity of Generation Z learners.

Structured inquiry is a shift in from traditionally structured, often described as "cookbook" experiences to authentic research-based experiences (Brownell, Kloser, Fukami, and Shavelson, 2013). The reform movement in science education has led "old-style labs" (or cookbook labs) to be an inquiry process (Lo, 2013). We agree with A. Loukomies et al. (2013) that well designed activity (at our case structured inquiry activity) encompasses support for new generation learners' basic psychological needs and especially for support for social relatedness. The structured inquiry digital labs ensure the feeling of trust and the expectations of friendship of eighth-form school students: It is likely that this person and I could become friends if we interacted a lot $\left(\bar{x}_{d 4}=63,93 \pm 4,05\right)$; I felt like I could really trust this person $\left(\bar{x}_{d 2}=68,48\right.$ $\pm 4,02$ ). Evidence of positive interdependence, promotive interaction, individual accountability, social skills is characterized by virtual communication on physics experiments (Lo, 2013). The real physics labs based on the structured inquiry activity also allow the feeling of trust and the expectations of friendship of school students: It is likely that this 
person and I could become friends if we interacted a lot ( $\left.\bar{x}_{r 5}=69,39 \pm 3,67\right)$; I felt like I could really trust this person ( $\bar{x}_{r 2}$ $=72,42 \pm 3,63$ ). It means that real labs are important for fostering the communication of new generation school students.

"Teachers and students often have I-You relationships. In the workplace, must of us have many I-You relationships" (Wood, 2013; p.19). The results of our research show that the digital and real physics labs allow to reach a high level of communication: not only the second level (I-You) of communication but the highest - third - level of communication (I-Thou). It means that eighth-form school students interact at physics labs not only according to their social roles but also personally. On the other hand, interpersonal communication activity at physics labs can remain at the thirst level of communication (I-It). The results of our research show that a big part of school students feel really distant to people of lab groups (real labs $\bar{x}_{r 1}=40,30 \pm 3,46$; digital labs $\bar{x}_{d 1}=36,36 \pm 3,05$ ); and do not trust people from lab groups (real labs $\bar{x}_{r 4}=43,33 \pm 3,41$; digital labs $\bar{x}_{d 4}=42,42 \pm 3,72$ ).

\section{Conclusion}

Physics labs based on structured inquiry provide conditions for the interpersonal communication of the students of different levels in a lab group: interpersonal distance and distrust (level I-It); expectations of friendship and interpersonal interaction (level I-You); interpersonal trust and closeness (level I-Thou). Both real and virtual labs based on structured inquiry, enable a student to achieve the (I-You) and the third (I-Thou) levels of communication. However, in both cases real and digital labs - communication of the lowest level (I-It) is also manifested. It is (I-It) statistically significantly weaker than communication of the second (I-You) and the third (I-Thou) levels.

Digital labs shorten the time of real communication of students, as digital labs are accomplished using Digital laboratory software Xplorer GLX, which conducts tabulation, provides the data and draws graphical representation of the data. Therefore, the time of learners' experimental activity in the virtual environment id prolonged. It determines their attitude towards interpersonal communication. It appeared that a statistically significantly smaller number of eighth-form students stated that It is likely that this person and I could become friends if we interacted a lot after digital labs. Hence, accomplishing digital labs in groups according the methodology of structured inquiry develops weaker expectation for friendship in the future.

\section{References}

Bajpai, M. (2013). Developing Concepts in Physics Through Virtual Lab Experiment: An Effectiveness Study. Te chn o L E A R N : An International Journal of Educational Technology. 3 (1), 43-50.

Banchi, H., Bell, R., 2008. The Many Levels of Inquiry. Science and Children, 46 (2), 26-29.

Buber, M. (1970). I and thou (Walter Kaufmann, Trans.). New York: Scribner.

Dalgarno, B., Lee, M.W., 2010. What are the learning affordances of 3D virtual environments? British Journal of Educational Technology, 41(1), 10-32.

DeHaan, R.L. (2005). The impending revolution in undergraduate science education. Journal of Science Education and Technology 14(2), 253-269.

Etkina, E., Karelina, A., Ruibal-Villasenor, M., Rosengrant, D., Jordan, R. \& Hmelo-Silver, C.E. (2010). Design and Reflection Help Students Develop Scientific Abilities: Learning in Introductory Physics Laboratories. Journal of the Learning Sciences, 19 (1), $54-$ 98.

Hinton, T., Yeomanc, P., Carvalhob, L., Parisioc, M., Dayb, M., Byrnee, S., Bellf, A., Donohoeg, K., Radfordh, J., Tregloanb, P., Poronnikb, P. \& Goodyearb, P. (2014). Participating in the Communication of Science: Identifying Relationships Between Laboratory Space Designs and Students' Activities. International Journal of Innovation in Science and Mathematics Education, 22(5), 30-42.

Igwebuike, T. \& Oriaifo, S. (2012). Effect of a Constructivist Instructional Strategy on Affective Outcomes by Integrated Science Students. International Review of Contemporary Learning Research. 3(1), 1-10.

Jaakkola, T. \& Nurmi, S. (2008). Fostering elementary school students' understanding of simple electricity by combining simulation and laboratory activities. Journal of Computer Assisted Learning, 24(4), 271-283.

Kloser, M.J., Brownell, S.E., Shavelson, R.J. \& Fukami, T. (2013). Effects of a Research-Based Ecology Lab Course: A Study of Nonvolunteer Achievement, Self-Confidence, and Perception of Lab Course Purpose. Journal of College Science Teaching. Vol. $42(2), 90-99$.

Lo, H-Ch. (2013). Design of Online Report Writing Based on Constructive and Cooperative Learning for a Course on Traditional General Physics Experiments. Journal of Educational Technology \& Society Vol. 16 (1), 380-391.

Loukomies, A. Pnevmatikos, D., Lavonen, J, Spyrtou, A., Byman, R, Kariotoglou, P. \& Juuti, K.(2013). Research in Science Education.43 (6), 2517-2539. 
McCrindle, M. \& Wolfinger, E. (2010).The ABC of XYZ: Understanding the Global Generation. Australia: University of New South Wales Press Ltd.

Nedic, Z., Machotka, J. \& Nafalsk, A. (2003). Remote laboratories versus virtual and real laboratories. November 58, 33rd ASEE/IEEE Frontiers in Education Conference. Downloaded from http://www.icee.usm.edu/ICEE/conferences/FIEC2003/papers/1077.pdf

Petersson, E., Andersson, A. \& Säljö, R. (2013). Exploring Nature through Virtual Experimentation. Nordic journal of digital literacy (3), 139-156

Rosen, L.D. (2012). iDisorder. Understending our obsession with technology and overcoming its hold on us. US:PALGRAVE Macmillan.

Ryan, R. M. (1982). Control and information in the intrapersonal sphere: An extension of cognitive evaluation theory. Journal of Personality and Social Psychology, 43, 450-461.

Winn, F.S., Sarason, R., Fruland, P.O., Lee, Y-L. (2006). Learning oceanography from a computer simulation compared with direct experience at sea. Journal of Research in Science Teaching, 43(1), 25-42.

Wolf, S.J. \& Fraser, B.J. (2008). Learning environment, attitudes and achievement among middle-school science students using inquirybased laboratory activities. Research in Science Education, 38, 21-341.

Wood, J. (2013). Interpersonal communication. Everyday encounters. Canada: Wadsworth. 